\title{
The Caenorhabditis elegans spe-26 gene is necessary to form spermatids and encodes a protein similar to the actin-associated proteins kelch and scruin
}

\author{
Jacob P. Varkey, ${ }^{1}$ Paul J. Muhlrad, Alicia N. Minniti, Bao Do, and Samuel Ward ${ }^{2}$ \\ Department of Molecular and Cellular Biology, University of Arizona, Tucson, Arizona 85721 USA
}

\begin{abstract}
Six independent mutations in the Caenorhabditis elegans spe-26 gene cause sterility in males and hermaphrodites by disrupting spermatogenesis. Spermatocytes in mutants with the most severe alleles fail to complete meiosis and do not form haploid spermatids. Instead, these spermatocytes arrest with missegregated chromosomes and mislocalized actin filaments, endoplasmic reticulum and ribosomes. In spite of this arrest some of the nuclei and the organelles that normally transport sperm-specific components to the spermatid mature as if they were in spermatids. The spe-26 gene is expressed throughout the testis in both spermatogonial cells and spermatocytes. It encodes a 570-amino-acid polypeptide, which contains five tandem repeat motifs, each of $\sim \mathbf{5 0}$ amino acids. These repeats are similar in sequence to repeats in the Drosophila kelch protein, in the invertebrate sperm protein scruin that cross-links actin filaments, as well as in the mouse and pox virus proteins. The functional importance of these repeat motifs is shown by the fact that five of the spe-26 mutations are in the tandem repeats, and one of the most severe mutations is a substitution in a highly conserved glycine. These results suggest that spe-26 encodes a cytoskeletal protein, perhaps actin binding, which is necessary to segregate the cellular components that form haploid spermatids.
\end{abstract}

[Key Words: Spermatogenesis; sperm differentiation; meiosis; intracellular localization; kelch repeats]

Received January 2, 1995; revised version accepted March 20, 1995.

Cellular differentiation involves the ordered expression of genes and the localization, interaction, and assembly of their products to form a specialized cell. Mutations that disrupt cellular differentiation provide a way to identify the roles of individual genes in this complex process. Spermatogenesis in the nematode Caenorhabditis elegans is a particularly well-suited system for such genetic dissection because mutations specifically affecting spermatogenesis can be readily recognized by their hermaphrodite-sterile phenotype and recovered by mating mutant hermaphrodites to males. Spermatogenesis defects in such sterile mutants can then be studied in detail in males, which normally make many sperm. More than 60 spermatogenesis-defective (spe) genes have been identified and their mutant phenotypes ordered in the pathway of sperm development (L'Hernault et al. 1988, 1993; Shakes and Ward 1989; L'Hernault and Arduengo 1992; Varkey et al. 1993; and references therein).

Remarkably, of the 12 sperm-specific genes that have been cloned and characterized until the present, none shows significant sequence similarity to other genes

\footnotetext{
'Present address: Department of Biological Sciences, Humboldt State University, Arcata, California 95521.

${ }^{2}$ Corresponding author.
}

presently in the sequence data bases (Burke and Ward 1983; Klass et al. 1984; L'Hernault and Arduengo 1992; L'Hernault et al. 1993; S. Ward, unpubl.). The absence of homologs suggests that many distinctive proteins participate in the differentiation of $C$. elegans spermatozoa. This may not be surprising, as these unusual ameboid spermatozoa crawl by means of a single pseudopod with little or no actin and maintain their shape without microtubules (Wolf et al. 1978; Ward et al. 1981; Nelson et al. 1982; Roberts and Ward 1982).

In this paper we report phenotypic and molecular analysis of spe-26, a gene whose mutant phenotype disrupts the segregation of cellular components necessary to form spermatids-the haploid cells resulting from meiosis which activate to form spermatozoa. The spe-26 protein sequence contains a repeat motif that has been found in several proteins from other organisms, some of which play a role in cytoskeletal assembly and function.

\section{Results \\ Phenotype}

Six strains were obtained with mutations in the spe-26 gene as described in Materials and methods. Two have 
Table 1. Progeny and spermatids from spe-26 mutant and wild-type $(+/+)$ strains

\begin{tabular}{|c|c|c|c|c|}
\hline \multirow[b]{2}{*}{ Allele } & \multicolumn{3}{|c|}{$\begin{array}{c}\text { Self-progeny/ } \\
\text { hermaphrodite }\left({ }^{\circ} \mathrm{C}\right)\end{array}$} & \multirow{2}{*}{$\begin{array}{c}\begin{array}{c}\text { Male } \\
\text { spermatids }\end{array} \\
\left(25^{\circ} \mathrm{C}\right)\end{array}$} \\
\hline & 16 & 20 & 25 & \\
\hline$+1+$ & $336 \pm 37$ & $308 \pm 11$ & $201 \pm 3$ & ++++ \\
\hline spe-26(hc140ts\} & $14 \pm 12$ & $3 \pm 6$ & 0 & - \\
\hline spe-26|hc139ts) & $15 \pm 9$ & $2 \pm 3$ & 0 & - \\
\hline spe-26|hc138ts) & $111 \pm 36$ & $47 \pm 30$ & 0 & + \\
\hline spe-26(it112ts) & $294 \pm 57$ & $156 \pm 22$ & 0 & ++ \\
\hline spe-26|eb8) & 0 & 0 & 0 & ++ \\
\hline
\end{tabular}

Progeny are from hermaphrodites at three different temperatures. Each value is the mean and standard deviation of 9 or 10 individual hermaphrodites. Spermatids are estimated from several adult males of each strain grown at $25^{\circ} \mathrm{C}$. Wild-type males each produce $\sim 2000.1++|100-1000 ; 1+|<100 ; 1-\mid$ none.

identical mutations (see below); therefore, five of the mutant strains were characterized in detail. spe-26 mutant hermaphrodites homozygous for any of these mutations lay unfertilized oocytes instead of embryos. If such hermaphrodites are mated with wild-type males, their oocytes are fertilized by the male sperm, showing that the sperm of hermaphrodites is defective. spe-26 males are also sterile, although they appear to mate normally. Four of the alleles are temperature sensitive, being completely sterile at $25^{\circ} \mathrm{C}$ but producing various numbers of progeny at $20^{\circ} \mathrm{C}$ and $16^{\circ} \mathrm{C}$. One allele, eb8, causes sterility at all three temperatures (Table 1). Consistent with the defects in spermatocytes, temperature-shift experiments with three spe-26 mutant strains (hc138ts, hc139ts, and hc140ts) showed that the temperature-sensitive period in hermaphrodites is around the L4 to adult molt in both shift-up and shift-down experiments /data not shown). This period corresponds with spermatogenesis. All spe-26 alleles are recessive. When their phenotypes were tested over the deficiency $m D f 7$ at $25^{\circ} \mathrm{C}$ they were all sterile, as they are as homozygotes, with no additional phenotypes.

To determine where in the spermatogenesis pathway spe-26 mutants are defective, the gonads of adult virgin males and young hermaphrodites raised at $25^{\circ} \mathrm{C}$ were examined by light microscopy. Mutants homozygous for the alleles hc139ts and hc140ts produce almost no spermatids; hc138ts produces a few; and it112ts and $e b 8$ produce about half the normal number of spermatids (Table 1). Spermatid production for each of these mutations was examined over the deficiency $m D f 7$ at $25^{\circ} \mathrm{C}$. The phenotype of alleles hc139ts and hc140ts was unchanged, but the other three alleles produced fewer spermatids than as homozygotes. This suggests that the three alleles that yield spermatids (hc138ts, it112ts, and $e b 8$ ) are hypomorphic and not null. The spermatids that are made in worms homozygous for these three mutations appear normal in shape, although they vary in size more than wild type. They can be activated in vitro to produce spermatozoa with motile pseudopods (data not
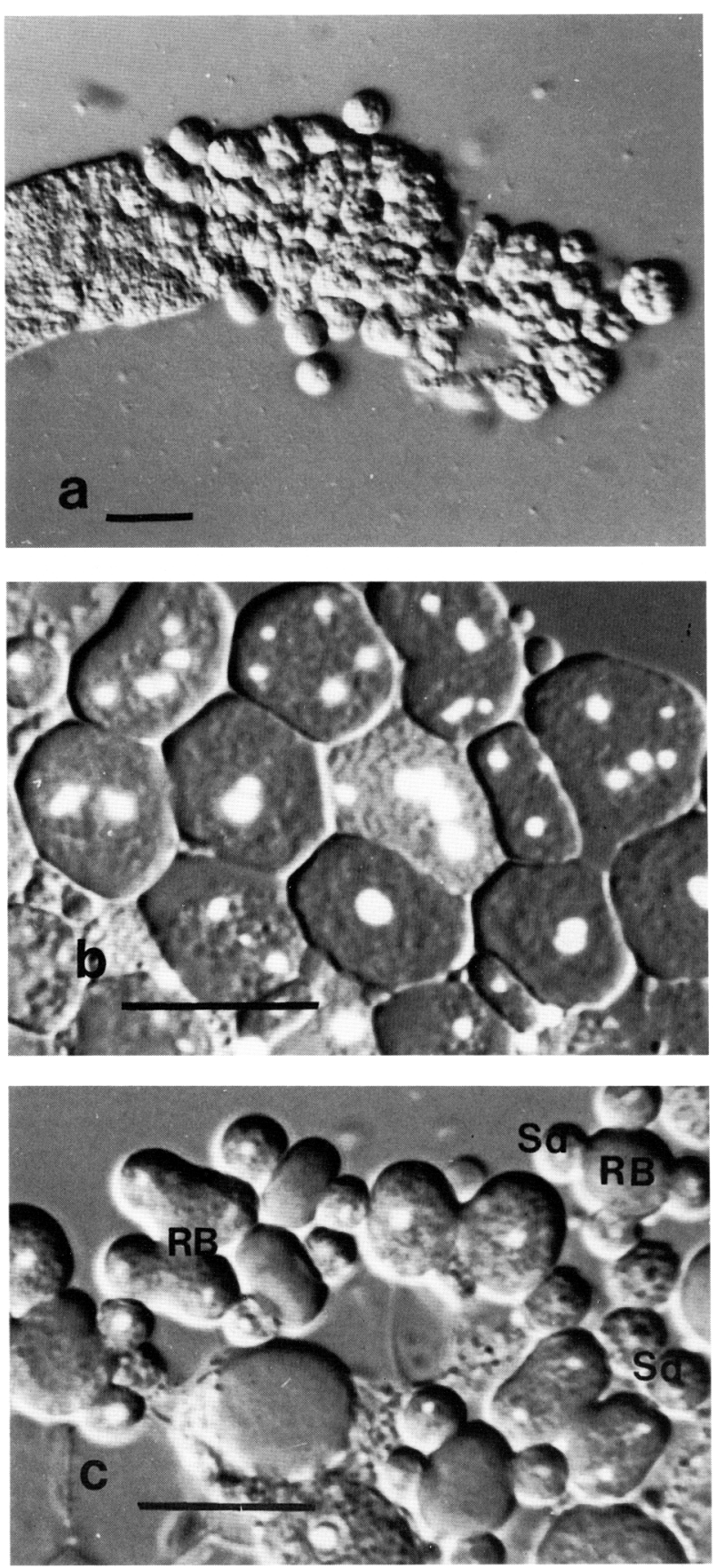

Figure 1. Light micrographs of mutant and wild-type spermatocytes. Micrographs are with Nomarski optics alone or Nomarski optics combined with fluorescence to show DAPIstained nuclei and chromosomes as bright spots. (a) spe-26 (hc140ts) mutant testis fragment. The large, spherical, granular cells are arrested spermatocytes; no spermatids are found. $(b)$ Higher magnification of mutant spermatocytes showing many DAPI-stained regions in some spermatocytes. (c)Wild-type spermatocytes undergoing normal development. Spermatids (Sd) can be seen budding off from residual bodies (RB) and as fully separated cells. Bar, $10 \mu \mathrm{m}$. 
shown). Thus, the spermatids that are produced are able to proceed through spermiogenesis to form the spermatozoa. Nonetheless, in vivo these mutants are completely sterile at the restrictive temperature; therefore, any spermatozoa formed must be incapable of fertilization.

In all spe-26 mutant strains, spermatogenesis appears to proceed normally through the formation of primary spermatocytes. Subsequently, the spermatocytes fail to complete meiosis. They remain as large, round cells with a granular appearance under differential interference contrast microscopy, and they fail to form spermatids (Fig. la). When stained with DAPI to reveal nuclei and chromosomes, all defective spermatocytes showed multiple DAPI-positive regions (Fig. 1b). Nearly half had four condensed DAPI-positive regions, suggesting that both the first and second meiotic divisions had proceeded. The remaining spermatocytes had more than four DAPIstaining regions; as many as 12 were observed. Staining intensity was variable, indicating varying numbers of chromosomes. This suggests that chromosome segregation is defective in many of the spermatocytes. To de- termine whether there were gross alterations in the spindles at this stage, mutant spermatocytes were stained with anti-tubulin antibodies. Many spermatocytes showed normal-looking spindles (Fig. 2a,b). In wild-type cells the spindles, together with other organelles, are segregated into the residual body cytoplasts, which are subsequently degraded (Fig. 2c,d; Ward 1986). This suggests that the mutant spermatocytes arrest development and retain their assembled spindles.

In spe-26 mutant spermatocytes, aberrant segregation of cell components is not limited to chromosomes. In wild-type spermatocytes, actin segregates to the center of the dividing cells, where it becomes sequestered into the residual body (Fig. 2h,i; Ward 1986). When spe-26 mutant spermatocytes were stained with rhodamineconjugated phalloidin, actin filaments were seen aggregated to one side of the undivided cells instead of accumulated in the center (Fig. 2e-g).

Spermatogonial cells and early primary spermatocytes appeared normal when spe-26 mutant testes were examined by electron microscopy, as they did with light microscopy. All of the organelles found in wild-type sper-
Figure 2. Tubulin and actin staining of mutant and wild-type spermatocytes. $(a, b)$ Confocal images of spe-26 (hc140ts) mutant spermatocytes, (a) YO-PRO stained to show nuclei; $(b)$ anti-tubulin staining showing large spindles in essentially all of the arrested spermatocytes. $(c, d)$ wild-type spermatocytes. (c) Nomarski optics, residual bodies labeled RB $(d)$ anti-tubulin showing spindles remaining in residual bodies; $(e, f)$ spe-26 (hc140ts) mutant spermatocytes stained with DAPI $(e)$ or rhodamine-conjugated phalloidin $(f) ;|g|$ confocal image similar to $f$. The rhodamine-conjugated phalloidin staining shows actin filaments concentrated at the periphery of the defective spermatocytes. (h,i) Wild-type spermatocytes and spermatids. (h) Nomarski optics; (i) rhodamineconjugated phalloidin staining showing actin filaments throughout the residual bodies but not in spermatids. (c,d,h and i) Modified with permission from Ward (1986). Bars, $10 \mu \mathrm{m}$.

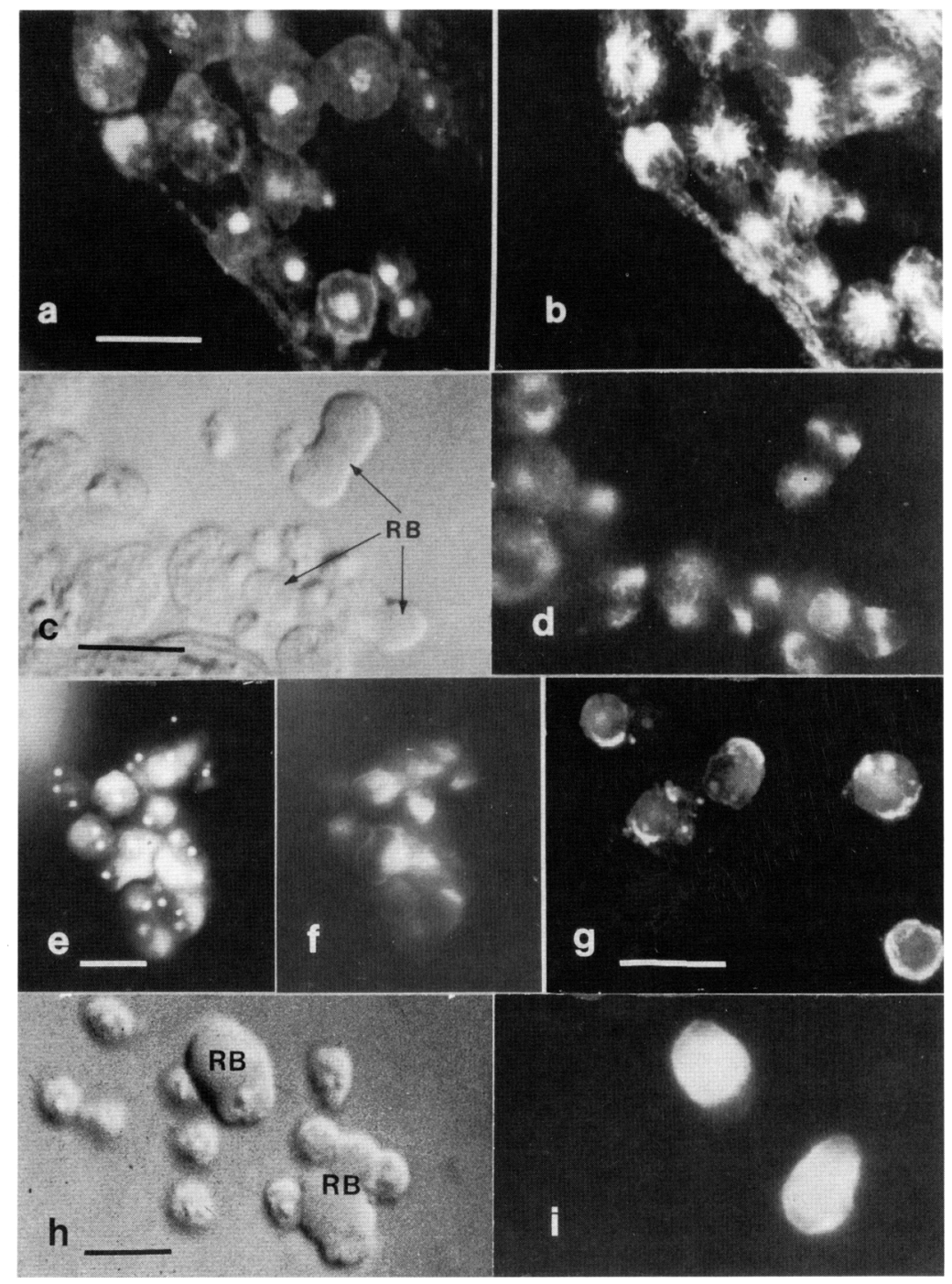



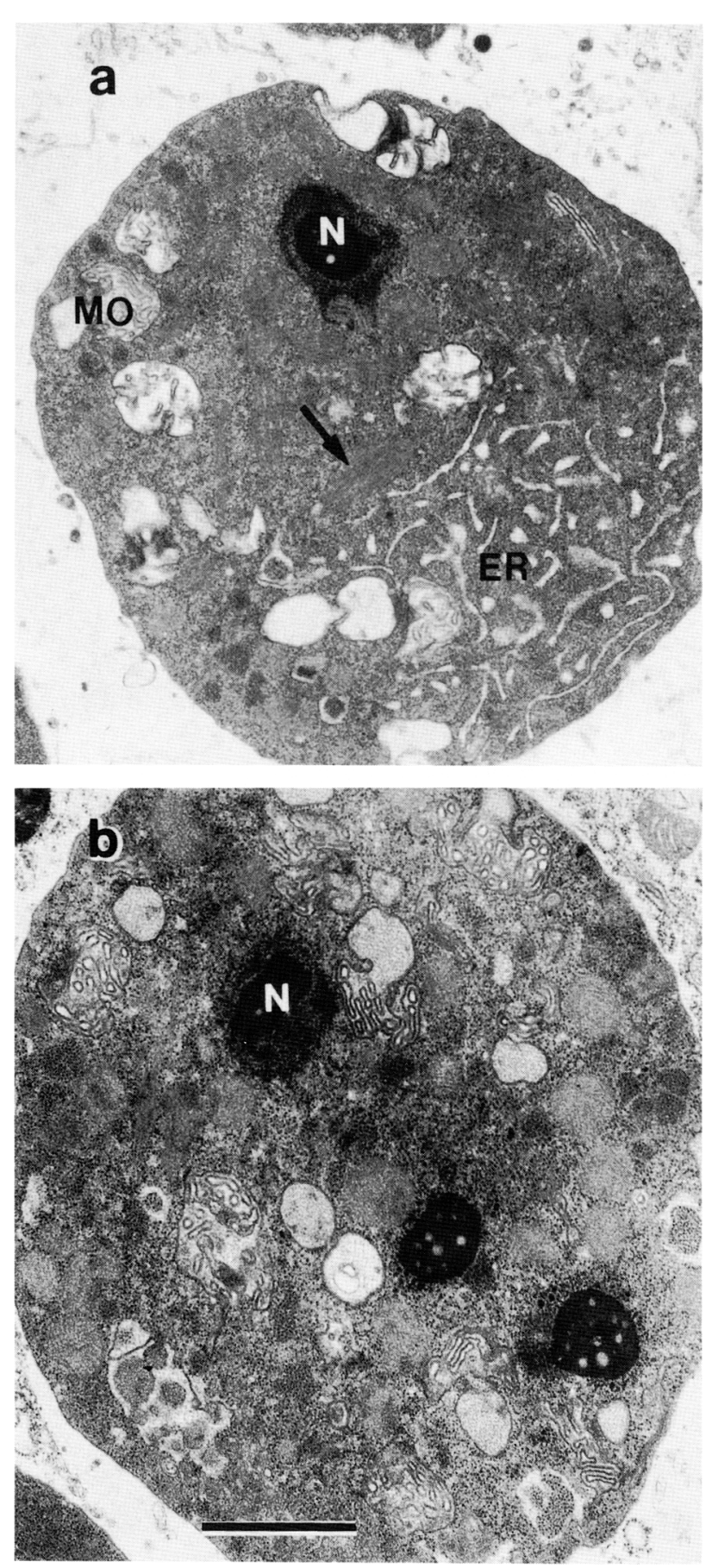

Figure 3. Transmission electron micrograph of spe-26 (hc140ts) mutant spermatocytes. (a) A single nucleus (N) shows fully condensed chromatin surrounded by a perinuclear halo as in the nucleus of a spermatid. A fibrous body (arrow) has begun to disassemble, and most of the MOs (large electron lucent vesicles) have separated from their fibrous bodies and become compact as they would in a spermatid. The ER has congregated at the periphery of the cell, not in the center as it would in a normal secondary spermatocyte; ribosomes remain throughout the cytoplasm instead of congregating in the center. $(b)$ Three nuclei are seen in this section, and again the MOs are compact and the fibrous bodies have disassembled as in a normal spermatid. Bar, $1 \mu \mathrm{m}$. matocytes are present in mutant spermatocytes. The fibrous body-membranous organelle (FB-MO), which contains parallel arrays of major sperm protein (MSP) filaments surrounded by a folded double membrane, appears normal in the primary spermatocytes. In wild type, this organelle serves to segregate sperm-specific components to the spermatid (Roberts et al. 1986). In the spermatid the FB-MO disassembles; therefore, the MSP becomes distributed throughout the cytoplasm and the MO membranes fold into the characteristic dumbbell shape of the mature MO (Wolf et al. 1978; Ward et al. 1981; Ward and Klass 1982; Roberts et al. 1986). In spe26 mutant spermatocytes, the FB-MO complex disassembles in the spermatocytes themselves and the MSP filaments disperse (Fig. 3). The MO membranes do fold into a compact structure, but they become distended in some mutant spermatocytes.

As observed with light microscopy, spe-26 mutant spermatocytes show multiple nuclei by electron microscopy (Fig. 3). In some mutant spermatocytes these nuclei have fully condensed chromatin surrounded by a halo of less electron-dense material as seen in normal spermatid nuclei. The mutant spermatocytes also show mislocalization of the endoplasmic reticulum (ER) and of ribosomes. The ER, instead of segregating to the center of the spermatocyte where it would become part of the residual body, becomes mislocalized to the periphery of the cell, as was observed for actin (Fig. 3). Normally, all ribosomes segregate to the residual body, leaving the spermatids free of ribosomes. In spe-26 mutant spermatocytes the ribosomes remain throughout the cytoplasm (Fig. 3).

\section{Transformation rescue}

Genetic mapping located spe-26 near and to the left of mec-3. Because mec-3 was located on the physical map, cosmid clones from this region were obtained from $\mathrm{A}$. Coulson (Medical Research Council, Cambridge, UK) and assayed for their ability to restore fertility to spe26(hc138ts) hermaphrodites by microinjection transformation (Fig. 4). Only cosmid clone $\mathrm{C} 26 \mathrm{H} 10$ restored fertility at $25^{\circ} \mathrm{C}$. Various restriction fragments of the 40 kbp genomic DNA insert in this cosmid were subcloned and assayed for spe-26 activity by transformation rescue. A 6.5-kbp HindIII fragment restored spe-26(hc138ts) fertility to $108 \pm 61$ progeny per hermaphrodite, approximately half the wild-type levels at $25^{\circ} \mathrm{C}$ (Table 1 ).

The $6.5-\mathrm{kbp}$ fragment was used as a probe for differential Northern blot analysis to characterize the transcripts it encodes. Two transcripts were observed (Fig. 5). The larger transcript was found only in RNA isolated from worms making sperm: wild-type males and fem-3(q23ts) mutant worms, which have a hermaphrodite somatic morphology but produce only sperm and no oocytes. This transcript was not found in RNA isolated from "females" fem-1(hc17ts) mutant hermaphrodites, which produce oocytes, but no sperm. The $2.1-\mathrm{kb}$ transcript appears to be sperm specific, therefore it is likely to be the spe-26 transcript that is confirmed below. A second 
Figure 4. Genetic and physical map of the mec-3 region on chromosome IV showing the position of the spe-26 gene. The positions of deficiencies are shown above the genetic map, which has a scale bar in centimorgans ( $\mathrm{cM}$; right). The physical map is shown below the genetic map as successive expansions of the region that contains the spe-26 gene with the scale of each indicated at right. Restriction enzyme sites are shown below; $(\mathrm{H})$ HindIII; (E)EcoRI; (B)BamHI.

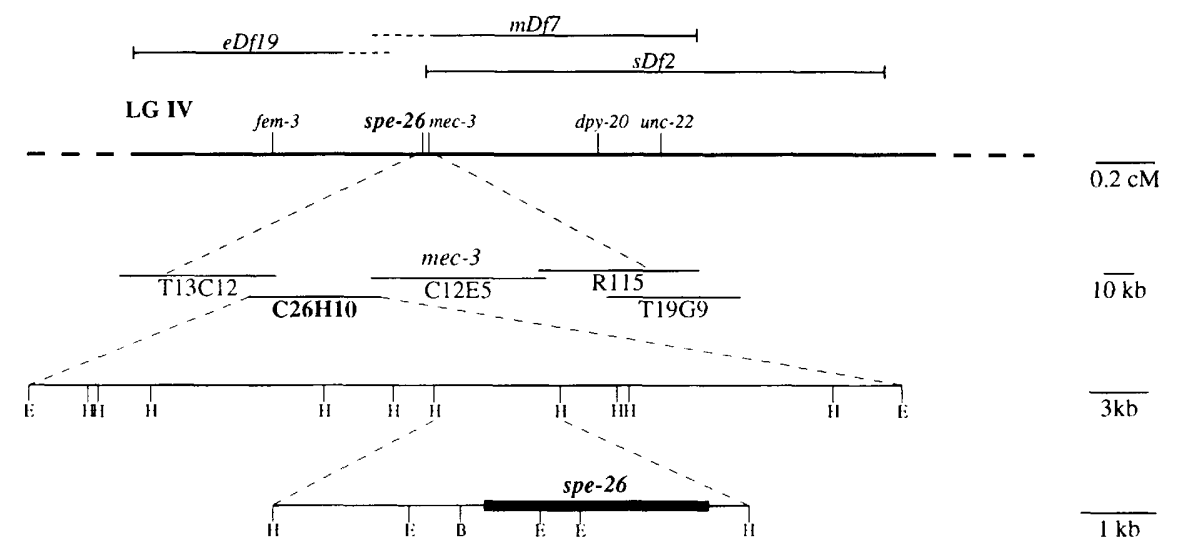

pendent spe-26 cDNA clones, were determined (Fig. 8). The spe-26 gene has six exons separated by small introns (Figs. 6 and 8). We confirmed that the largest cDNA clone, CDIV114, is nearly full length by a ribonuclease protection assay. A protected fragment was found only with RNA from worms making sperm. Its size indicated that the spe-26 mRNA extends no more than $\sim 10 \mathrm{nu}-$ cleotides $5^{\prime}$ to the $5^{\prime}$ end of CDJV114 (data not shown). On the basis of these results, we presume that the ATG

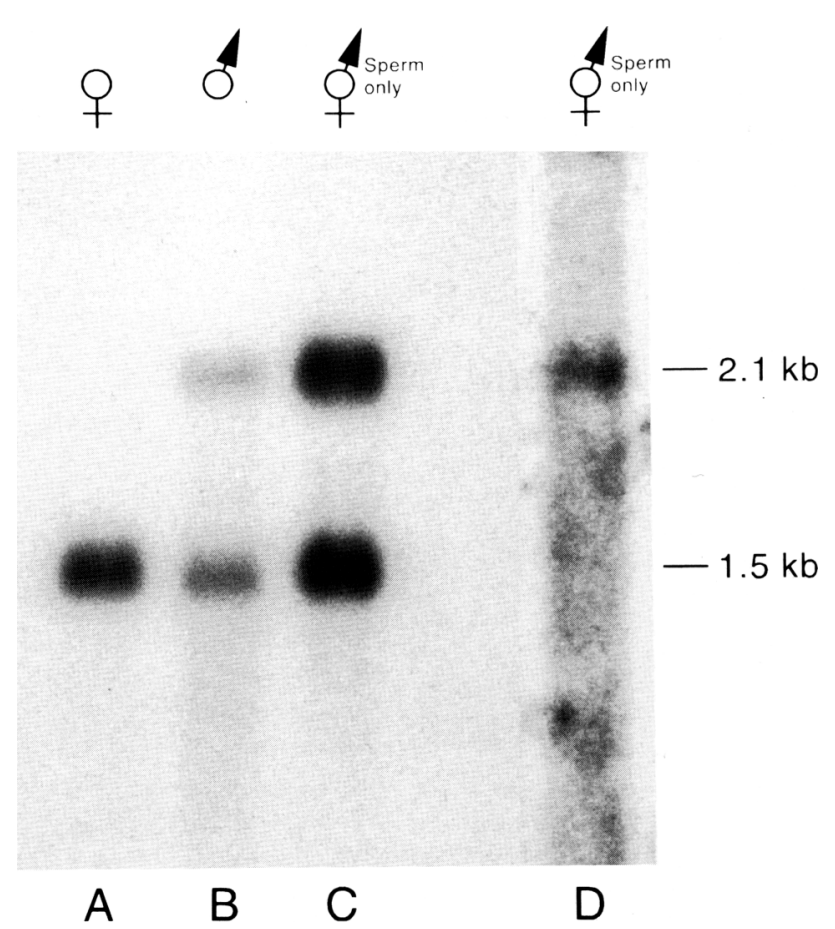

Figure 5. Differential Northern blot analysis showing the sperm-specific expression of the 2.1-kb spe-26 transcript. RNA was isolated from adult worms of fem-1(hc17ts), which produce only oocytes (lane $A$ ), males (lane $B$ ) and fem-3(q23ts), which produce only spermatids (lanes $C, D$ ). Lanes $A-C$ were probed with the $6.5 \mathrm{kbp}$ genomic fragment that rescued the sterile phenotype of spe-26 mutants. Lane $D$ was probed with a spe-26 cDNA fragment. 


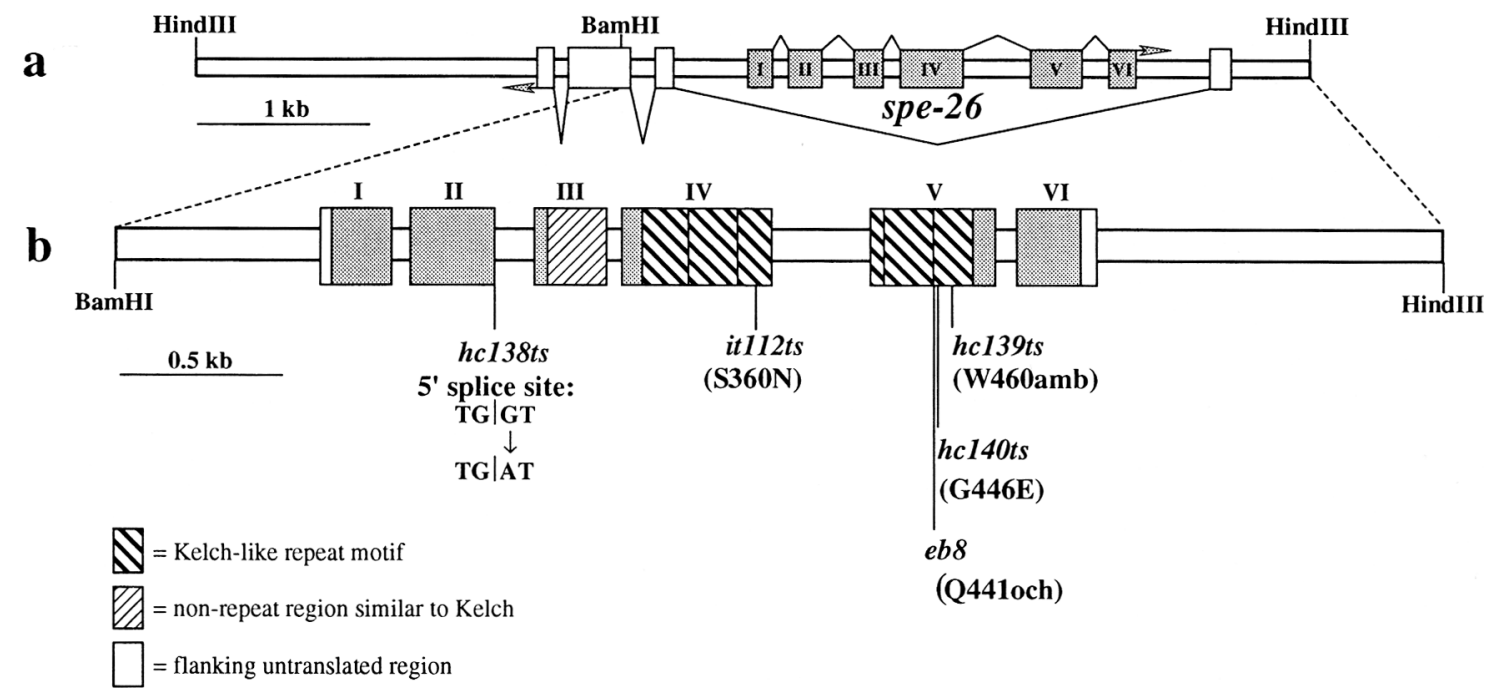

Figure 6. Structural organization of the spe-26 gene. $(a)$ The organization of the 6.5-kbp genomic fragment. On the basis of cDNA and genomic sequence comparison, the spe-26 gene (shaded) is contained in an intron of a somatically expressed gene (open boxes are exons) that is transcribed in the opposite direction from spe-26. (b) An expanded version of the spe-26 gene. The protein repeat domains similar to kelch are shaded with broad diagonal stripes, and a nonrepeat similarity (see Fig. 10b) is shaded with thin diagonal stripes. The position and identity of each of the five spe-26 mutations are shown below the gene.

positioned 23 bases downstream of the $5^{\prime}$ end of CDJV114 is the translation start site (Fig. 8). The nucleotides surrounding this codon also are similar to the $C$. elegans consensus for translation start sites (W.B. Wood, pers. comm.).

We studied the spe-26 gene and its potential regulatory regions by making $5^{\prime}$ and $3^{\prime}$ deletions in the genomic clone and testing their ability to restore fertility by transformation rescue. The results summarized in Figure 9 suggest that there is not a sharply defined promoter region. When DNA with deletions from the 5' side of the gene is injected into spe-26 mutant worms, deletions to -454 , to -392 , and to $-280 \mathrm{bp}$ from the start codon restore fertility almost as well as the complete gene. Deletions to -67 and to -15 are significantly less effective. Similarly, the 3' untranslated end can be deleted to within 92 bp from the termination codon and still restore fertility almost as well as the complete gene. As a control, a deletion to +171 into the first exon fails to restore fertility.

The sequences of the spe-26 genomic DNA, the mRNA-coding regions, and the predicted amino acid sequence of the SPE-26 protein were compared to the nucleic acid and protein data bases by the data base-searching algorithm BLAST (Altschul et al. 1990). Surprisingly, for the genomic DNA sequence, the most significant similarity found was to the region of the fourth and largest intron (293 bp) of the gene. This region shows high similarity to a large number of sequences from C. elegans. For those sequences from characterized genes (e.g., unc-93, ben-1, hlh-1), the regions of similarity are to known introns. For sequences from uncharacterized regions (e.g., cosmids that were sequenced as part of the $C$. elegans genome sequencing project), the regions of sim- ilarity are, for the most part, to regions postulated to be intron or noncoding intergenic sequences (Sulston et al. 1992). Using the Genetics Computer Group (GCG) sequence analysis software programs COMPARE and DOTPLOT (Devereux et al. 1984), we determined that this intron consists of an almost perfect inverted repeat sequence, which presumably can form a strong secondary structure in the RNA. Many, but not all, of the other C. elegans sequences with similarity to the intron also contain an inverted repeat structure. In some cases, only one-half of the repeat is present, and in other cases, a portion of each repeat half is present.

To test whether this conserved intron sequence has an essential role, we attempted to rescue a spe-26 mutant with a spe-26 genomic construct that had introns 4 and 5 deleted. This construct was made by replacing the $3^{\prime}$ genomic region with the corresponding region of the cDNA. Nine fertile transformed worms were obtained, and they had an average brood size of $71 \pm 29$ in contrast to a brood size of $108 \pm 61$ from worms transformed by the complete genomic fragment (Fig. 9). These differences are significant $(P=0.03$, by a $t$ test $)$; therefore this intron may have some role in spe-26 gene expression, but it is certainly not essential.

The spe-26 cDNA encodes a 570-amino-acid polypeptide. The most notable feature of the predicted protein is a series of five motifs of roughly similar sequence, $\sim 50$ amino acids long, repeated in tandem in the carboxyterminal half of the protein (see Fig. 6). A BLAST (version P) sequence search of the protein sequence data bases with the predicted SPE-26 polypeptide revealed that this 50 residue tandem repeat motif is a member of a family containing highly similar repeats. The first member of this family to be described was the kelch protein of 


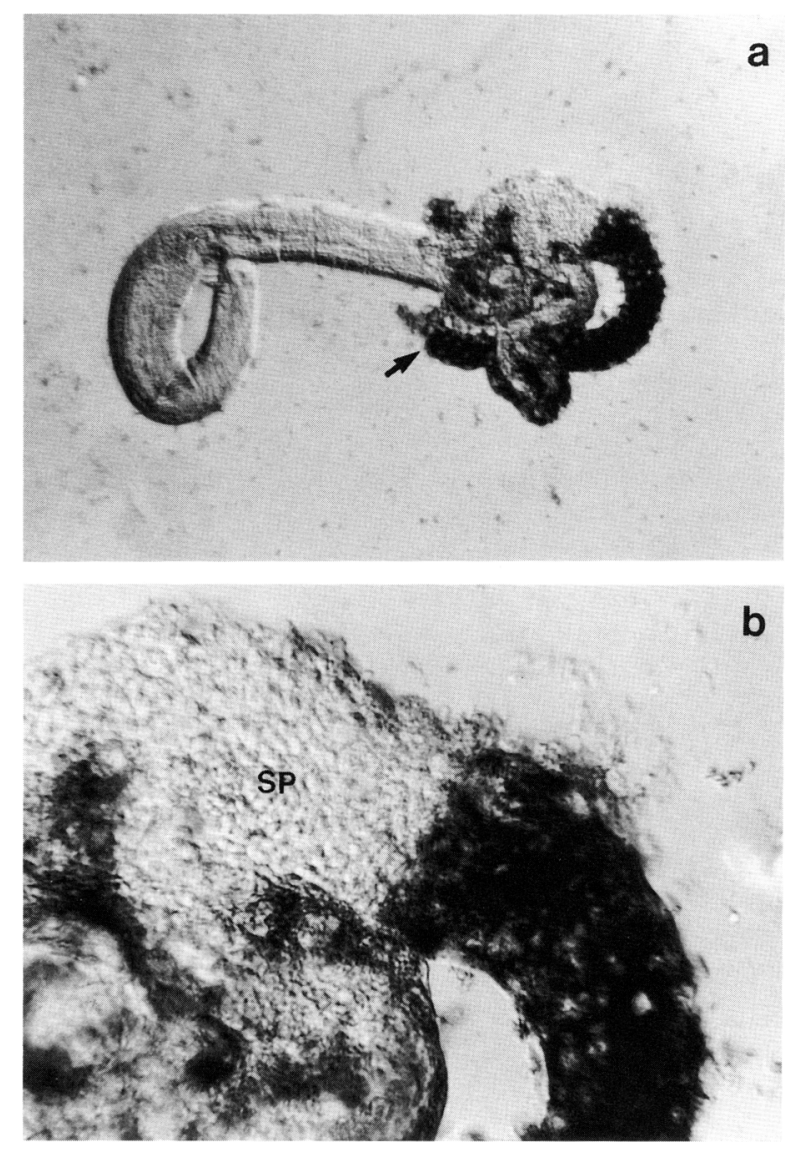

Figure 7. In situ hybridization of wild-type testis and worm carcass with a spe-26 cDNA probe. The dark regions show the areas expressing spe-26 mRNA. (a) An entire testis showing mRNA localization from the spermatogonial cells in the distal part of the testis (arrow) through spermatocytes. The dark staining of the intestine, which is to the left of the testis, is similar to that seen in the absence of probe; therfore, it is presumably attributable to alkaline phosphatase activity in the intestine. $(b)$ Higher magnification showing spe-26 mRNA in spermatocytes but not in spermatids (SP).

Drosophila melanogaster, which is a component of ring canals in Drosophila egg chambers (Xue and Cooley 1993). Other members of this family are MIPP, a mouse protein of unknown function (Chang-Yeh et al. 1991), scruin, an actin-bundling protein that is a component of acrosomal filaments in Limulus sperm (Owen and DeRosier 1993; Schmid et al. 1993, 1994) several proteins from pox viruses (Senkevich et al. 1993), and another protein from C. elegans predicted from the genome sequencing project (Wilson et al. 1994). Of these, the $C$. elegans protein shows the highest degree of similarity to SPE-26, followed by kelch (Fig. 10). For each of these tandem repeats the individual repeat elements are more similar to each other than to those of other species.

SPE-26 and kelch also share another region of sequence similarity of $\sim 60$ residues just amino-terminal to their respective repeat domains (Figs. $6 \mathrm{~b}$ and $10 \mathrm{~b}$ ). These regions are $\sim 50$ residues from the repeat region in kelch and 21 residues from the repeats in SPE-26. They show $29 \%$ amino acid identity and $54 \%$ similarity (Fig. 10b). When either of these second regions of similarity is used to search the protein data bases no additional significant matches are found.

\section{Mutations}

We determined the mutational alterations in all six spe26 alleles by cycle sequencing genomic fragments amplified from the spe-26 region of homozygous mutant worms of each strain. One and only one nucleotide substitution was found for each allele (Figs. 6b and 8). All five ethylmethane sulfonate (EMS) induced mutations were found to be $\mathrm{G} \rightarrow \mathrm{A}$ transitions, and the single psoralen-induced mutation is a $\mathrm{C} \rightarrow \mathrm{T}$ transition. The canonical allele hc138ts is a change from the obligate $G$ of the splice donor site of intron 2 , which presumably results in a splicing defect. Alleles it112ts, it118ts, and hc140ts all have missense mutations. it112ts and it118ts have the same base substitution, which results in a change of Ser-360 to Asn, and hc140ts results in a substitution of Gly-446 to Glu. The other two alleles are nonsense mutations: The nonconditional allele $e b 8$ is an ochre mutation of Gln-441; hc139ts is an amber mutation from Trp-460. Except for the putative splicing defect, all of the mutations are located within the kelchlike repeat domain. One of these, hc140ts is in the glycine pair of the fifth repeat unit, which is the most invariant feature of the motif (Fig. 10).

Because spe-26 (hc139ts) is an amber mutant, we attempted to suppress the sterile phenotype by transformation with a plasmid carrying the amber suppressor tRNA sup-7/st5) (Waterston 1981; Wills et al. 1983; Kondo et al. 1988). This is a difficult experiment because the spe-26 mutant is slightly fertile at $15^{\circ} \mathrm{C}$, where the suppressor is most effective; therefore, we settled on an intermediate temperature of $22.5^{\circ} \mathrm{C}$, where spe$26(h c 139 t s)$ is completely sterile. Fifteen spe-26(hc139ts) hermaphrodites were injected with the sup-7 plasmid plus the rol-6 plasmid as a marker for transformation. Three of the 177 roller progeny raised at $22.5^{\circ} \mathrm{C}$ were fertile, producing 14, 19, and 40 embryos, respectively. In contrast, no embryos were obtained from hundreds of spe-26 worms injected with the rol-6 plasmid alone. This suggests that the amber mutation in spe-26 (hc139ts) can be suppressed by the sup-7|st5| allele to produce some sperm capable of fertilization. Suppression is rare, however, presumably because of the temperature and dose sensitivity of sup-7.

\section{Discussion}

The spe-26 gene encodes a 2.1-kb mRNA. By differential Northern blot analysis this mRNA is found only in worms making sperm; by in situ hybridization it is seen solely in the male testis in both spermatogonial cells and spermatocytes, although low levels of expression elsewhere cannot be ruled out. The predicted protein encoded by spe-26 has 570 amino acids. The most striking 


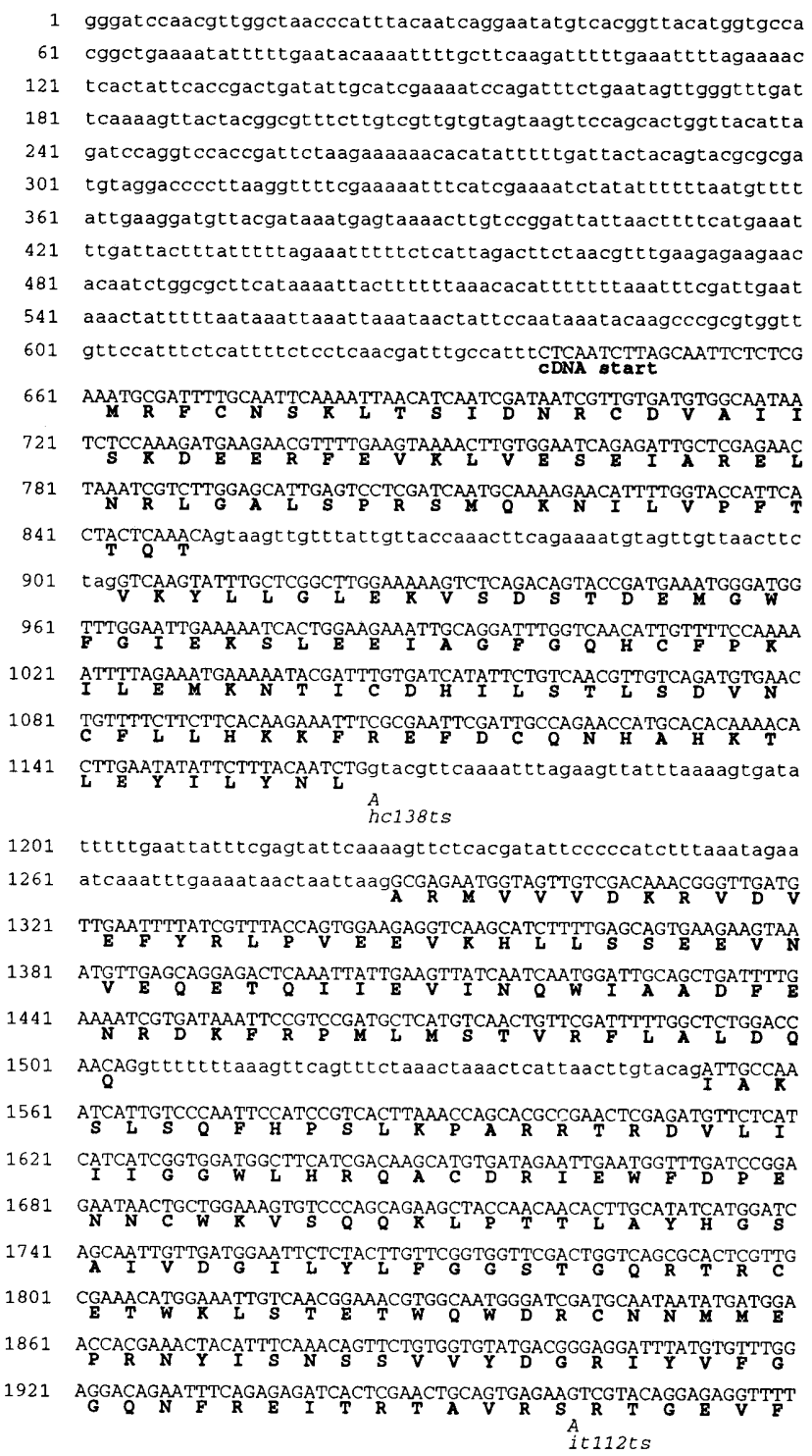

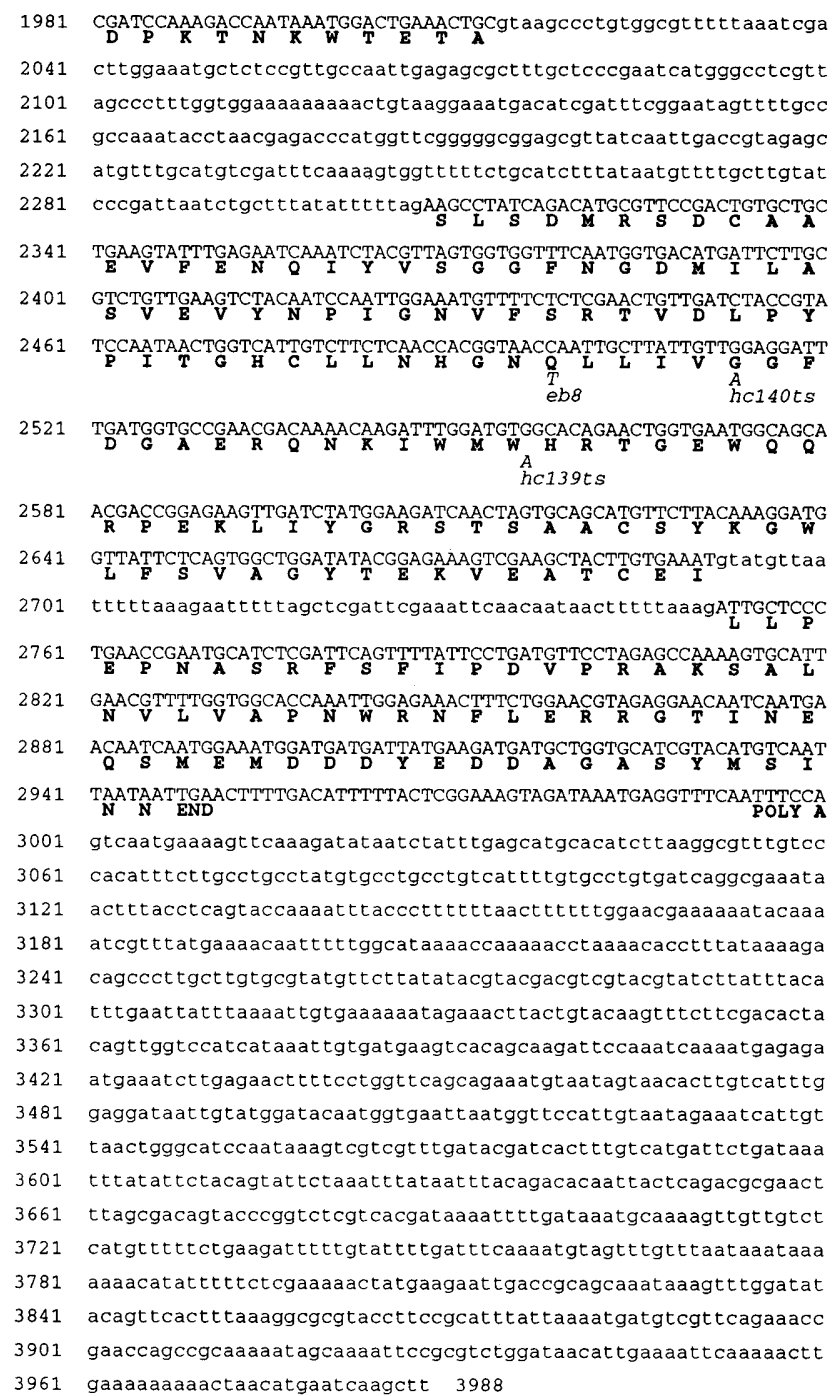

Figure 8. Nucleic acid sequence of the 3988-bp genomic fragment encoding the spe-26 gene with the predicted amino acid sequence of the SPE-26 protein and the positions and identities of the five mutations shown. Exons are shown with uppercase letters.

feature of this protein is a motif of $\sim 50$ amino acids that is repeated in tandem in the carboxy-terminal half of the protein. This tandem repeat is similar in sequence and arrangement to repeat motifs found in several other proteins. The repeat for which there is the most information about structure and function is scruin, which is an actin cross-linking protein that stabilizes Limulus sperm acrosomal microfilaments (Owen and De Rosier 1993; Schmid et al. 1993, 1994). The function of the Drosophila kelch protein is unknown, but it colocalizes with actin filaments that form the ring canals, which regulate nutrient transport from the nurse cells to the oocyte (Xue and Cooley 1993; Knowles and Cooley 1994). In addition to the similarity in the repeat motif, kelch, but not the other proteins, shares another region of sequence similarity with SPE-26. Little is known about the func- tion of the other proteins that contain this repeat motif, but the pox viruses do associate with actin as part of their intracellular movement (Perkins, et al. 1986; Kotwal and Moss 1988). It has been suggested that the repeat motif identifies a new family of actin-binding proteins (Knowles and Cooley 1994).

It remains to be established whether the repeat motifs themselves are actually actin-binding domains. Bork and Doolittle (1994) have used the repeat motif to establish a consensus sequence that has identified similar repeated domains in both prokaryotic and eukaryotic proteins, many of which are carbohydrate-modifying enzymes. The structure of one of these, a fungal galactose oxidase, has been established by crystallography. The individual repeat elements each form a four-stranded $\beta$ sheet. The six repeats in this protein then fold together forming a 


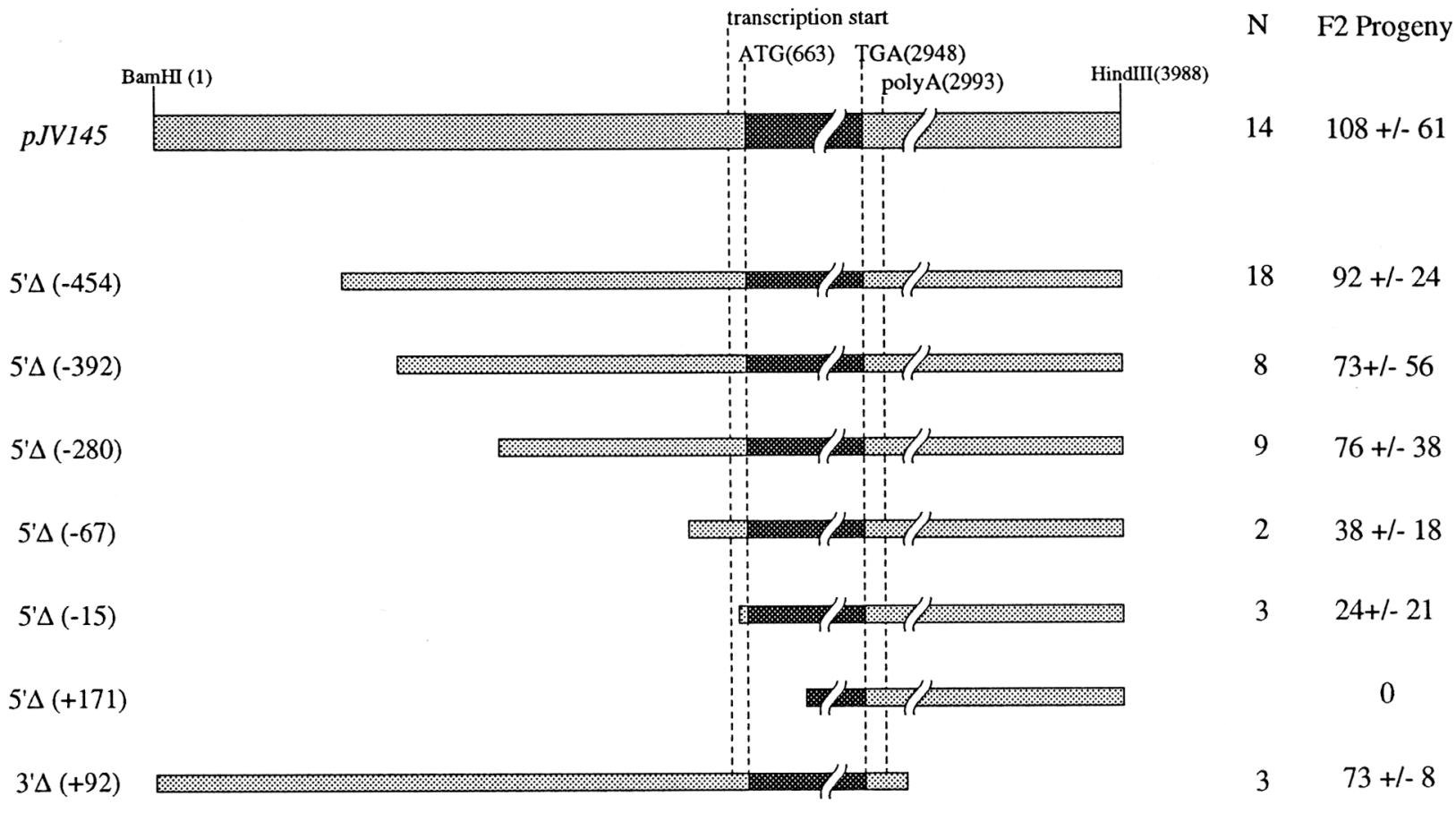

Figure 9. Transformation rescue with deletions. Diagrams show the $5^{\prime}$ and $3^{\prime}$ deletions of spe-26 that were used for transformation rescue of spe-26(hc138ts) worms, with the position of the $5^{\prime}$ deletions indicated as minus $(-)$ from the ATG start codon and the $3^{\prime}$ deletion as plus ( +) from the TGA stop codon. (N) Number of fertile roller animals obtained by cotransformation with each deletion plasmid and rol-6 plasmid marker. $\mathrm{F}_{2}$ progeny shows the mean and standard deviation of the number of progeny produced by the these fertile cotransformed worms. $\mathrm{N}$ is low for the more extensive deletions because the cotransformation frequency was so low that few fertile progeny were obtained, presumably because many worms that were successfully cotransformed produced no progeny; therefore, they were not included. Only the last four deletions are significantly different from the $p / V 145$ control by a $t$-test.

"propeller like" structure or a $\beta$ "superbarrel" (Brandon and Tooze 1991) that contains the catalytic unit. The sequence similarity between SPE-26 repeat domains and these proteins is much less than that between SPE-26, kelch and scruin, but it is possible that the repeat domains may reflect a conserved structural motif that could have different functions in different proteins.

The effects of mutations in the spe-26 gene are consistent with the idea that the SPE- 26 protein plays a role in the spermatocyte cytoskeleton, possibly interacting with actin. The positions of these mutations also confirm the importance of the repeat motif in protein function. All mutations disrupt chromosome segregation and the cytoplasmic rearrangements that are necessary for secondary spermatocytes to form spermatids and residual bodies. Three alleles appear to be hypomorphic by the criterion that they produce fewer spermatids in males when placed over a deficiency, although this does not alter their sterile phenotype. These are hc138ts, a splice site alteration in the second intron, it $112 t s$, a missense mutation in the third repeat element, and $e b 8$, an ochre chain termination mutation in the fifth repeat. The two remaining alleles have the most severe phenotypes, producing few spermatids, and probably represent null alleles. These are hc140ts, an alteration of a glycine in the fifth repeat element that is conserved in all of the homologous repeat motifs, and hc139ts, an amber muta- tion also in the fifth repeat. It is not clear why both an amber mutation (hc139ts) and a nearby ochre mutation (eb8) should not both be null. Perhaps there is some background readthrough or partial tRNA ochre suppression in the testis, or the polypeptide region carboxy-terminal to this mutation is dispensable. One puzzling aspect of these mutations is that the phenotype is temperature sensitive for all except $e b 8$. It is not apparent why amber mutations, splicing mutations, and missense mutations should all be temperature sensitive unless the process they control is temperature sensitive. If this were the case, then $e b 8$ should also be temperature sensitive.

The phenotype shared by all spe-26 mutant strains is that they are completely sterile at $25^{\circ} \mathrm{C}$. When the testes are examined in detail the putative null alleles arrest spermatogenesis at the stage of secondary spermatocytes and produce almost no haploid spermatids. In these arrested cells the chromosomes missegregate and often form multiple nuclei, the meiotic spindles remain assembled, the actin filaments mislocalize to patches in the cell periphery rather than in the center of the cell, the ER also mislocalizes to the periphery of the cell, and the cytoplasmic ribosomes remain distributed throughout the cell. In spite of arresting development as apparent secondary spermatocytes, the organelles in the cell continue to mature as if they were in spermatids: The 
a

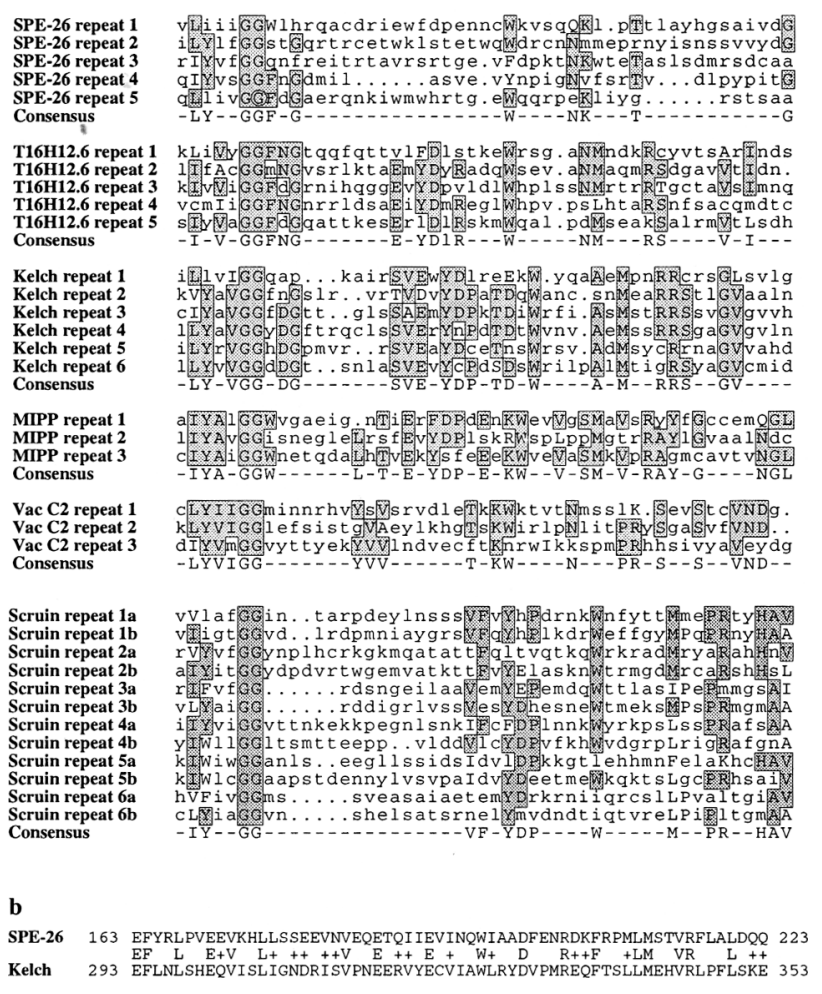

Figure 10. (a) Alignments of repeat subunits from the SPE-26 protein and five other proteins sharing this repeat motif. The alignments were performed by the GCG program modules PILE UP and PRETTY. Residues identical to the consensus sequence at each position are shaded and capitalized. Positions having conserved changes relative to the consensus are capitalized. Periods represent gaps inserted into the sequence by PILE UP to facilitate maximal sequence alignment. Dashes in the consensus sequence are at positions where there is no adherence to a consensus. The consensus for each position was assigned if at least five (for scruin), four (for kelch), three (for SPE-26, T16 12.6), or two (for MIPP and Vac C2) of the repeats have the same residue at that position. spe-26 mutant hc140ts has an alteration of the second $\mathrm{G}$ in the invariant diglycine in the fifth repeat unit (circled). The sequences are from SPE-26 (this paper), T16H12.6 (putative polypeptide encoded on C. elegans cosmid clone T16H12 (Wilson et al. 1994)], kelch [Drosophila melanogaster kelch protein (Xue and Cooley 1993)|, scruin [Limulus scruin protein (Way et al. 1994)], MIPP [murine IAP-promoted placenta-expressed gene (Chang-Yeh et al. 1991)], and Vac C2 [vaccinia virus C2 protein (Kotwal and Moss 1988)]. (b) The 61 -residue regions of sequence similarity between SPE-26 and kelch that are amino-terminal to the repeat domains (numbering corresponds to the respective polypeptides|. As indicated between the two regions shown, 18 residues are identical $(29 \%)$ and 33 are identical or similar,,$+(54 \%)$.

MSP fibers disassemble from the FB-MO complex, the MO membranes fold into a more compact form similar to the normal spermatid MO, and some nuclei complete DNA condensation and become surrounded by a perinuclear halo characteristic of spermatid nuclei. The persistence of the meiotic spindle is also characteristic of normal development, as in wild type the assembled spindle would be segregated into the residual body (Ward 1986). Such ongoing organelle development in arrested cells has been found for other spermatogenesis-defective mutants (L'Hernault and Arduengo 1992; Ward et al. 1981). These results show that the development of these organelles can proceed independently from the remainder of the cell.

The mutant phenotypes are consistent with a defect in an actin-binding protein, although they do not establish this rigorously. If this were the primary defect, it could explain the mislocalization of actin filaments, which in turn could cause the other observed cytoplasmic alterations. The mislocalization of ER and the uniform distribution of ribosomes could be attributable to actin filaments failing to segregate them, as ribosomes appear to be attached to the actin cytoskeleton (Singer 1992). Similarly, disruption of the cytoskeleton could lead to the missegregation of chromosomes. Alternative explanations for the mutant phenotypes are that the SPE-26 protein might be involved in the formation of membrane necessary to bud off the spermatids, or in the process of budding itself.

The regulation of spe-26 expression appears to depend on sequences $5^{\prime}$ to the gene, but deletions do not show sharply defined promoter or enhancer regions whose loss abolishes fertility. This may be because SPE-26 is only needed in small quantities; therefore, fertility is not a sensitive measure of spe-26 expression. In support of this, it was observed that if the concentration of the complete plasmid that rescues spe-26 mutants is reduced from 200 to $3 \mu \mathrm{g} / \mathrm{ml}$ before transformation, the success of transformation and the number of progeny produced by transformants is essentially unchanged /data not shown). Thus, the relatively small differences in fertility shown by the first four of the 5 ' deletions in Figure 9 may hide a much larger difference in spe-26 expression. In practice, this has proved valuable; restoration of fertility of spe-26 mutants is now used by several laboratories as a useful marker for DNA transformation.

In addition to the sterile phenotype of spe-26 mutations described here, some of these mutations have been found to increase nematode life span (Van Voorhies 1992) This increase results, at least in part, from the reduced sperm production in the mutants, as increased sperm production reduces life span in males. Whether this is the only cause of increased life span in these mutants remains to be determined.

\section{Materials and methods}

\section{Strains}

C. elegans var. Bristol, strain N2, was used as the wild type. The following genes were used for linkage analysis, two factor crosses, and three factor crosses: dpy-5(e61)I, dpy-11(e224)V, dpy-13(e184)IV, dpy-20(e1282ts)IV, lon-2(e678)X, rol-1(e91)II, unc-5(e53)IV, unc-22(e66)IV, unc-30(e191)IV, and unc32(e189)III. The deficiencies used in this analysis were $e D f 18$ (IV) and $e D f 19(I V)$ (Hodgkin 1986), sDf2(IV) and $m D f 7(I V)$ (Clark and Baillie 1992). The strains were maintained at appropriate temperatures on Escherichia coli (strain OP50)-seeded 
plates, and genetic manipulations were performed as described by Brenner (1974).

\section{Isolation and genetics of spe-26 mutations}

The canonical spe-26 allele hc138ts is an EMS-induced mutation isolated in a genetic screen for spe mutations linked to $d p y-13$ on chromosome IV similar to that used for obtaining chromosome I mutations (L'Hernault et al. 1988). Allele hc138ts was obtained by screening 2083 mutagenized chromosomes. Two additional alleles of spe-26, hc139ts and hc140ts, were isolated in an $F_{1}$ noncomplementation screen as follows. Young hermaphrodites marked for chromosome IV with $d p y$ 20(e1282ts) were EMS mutagenized and crossed with spe$26(h c 138 t s)$ males at the permissive temperature $\left(16^{\circ} \mathrm{C}\right)$. The outcross hermaphrodites were screened for sterility at the restrictive temperature $\left(25^{\circ} \mathrm{C}\right)$. Sterile worms from this $F_{1}$ generation were rescued by mating with wild-type males, and the new mutations linked to the marked chromosome were segregated and characterized further. Two additional independently isolated alleles, it112ts and it118ts, were identified by complementation tests from a group of EMS-induced chromosome IV mutations kindly provided to us by D. Shakes (University of Houston, TX). Sequencing these two alleles showed they both have the same mutation, therefore only one (it112ts) was characterized in detail. A sixth allele, $e b 8$, was identified from a group of psoralen-induced spe mutations kindly provided to us by S. L'Hernault (Emory University, Atlanta, GA).

The sterile phenotype of spe-26(hc138ts) mutant worms was mapped to the right arm of chromosome IV, under the deficiency $m D f 7$ between the breakpoints of the deficiencies $e D f 19$ and $s D f 2$ (Fig. 4). This was consistent with the two-factor and three-factor mapping of the sterile phenotype 0.7 map unit to the left of unc-22. The other four alleles, hc139ts, hc140ts, it112ts, and eb8, failed to complement hc138ts as well as the deficiency $m D f 7$ at the restrictive temperature. In addition, all five alleles failed to complement each other.

\section{Light microscopy}

Spermatogenesis was analyzed in both males and hermaphrodites by dissecting individual worms in sperm medium (SM) and examining them with Nomarski differential interference microscopy as described previously (Nelson et al. 1982). SM is 5 mM HEPES (pH 7.8) with $50 \mathrm{~mm} \mathrm{NaCl}, 25 \mathrm{~mm} \mathrm{KCl}, 5 \mathrm{~mm} \mathrm{CaCl}_{2}$, and $1 \mathrm{~mm} \mathrm{MgSO}$. To visualize nuclei, adult virgin males or young adult hermaphrodites were dissected in SM, and the gonads were transferred to a drop of $1 \mu \mathrm{g} / \mathrm{ml} \mathrm{4,6-diamidino-2-}$ phenylindole (DAPI) (Sigma, St. Louis, MO) in phosphate-buffered saline (PBS; $\mathrm{pH} 7.0$ ) on a slide and incubated in a dark moist chamber for $30 \mathrm{~min}$. The stained gonads were rinsed briefly in PBS and examined with UV illumination combined with Nomarski optics to visualize both the cells and their nuclei. To examine activation of spermatids to spermatozoa in vitro, adult virgin males or young adult hermaphrodites were dissected, and the spermatids were tested for the ability to form spermatozoa by adding Pronase or triethanolamine (Ward et al. 1983).

\section{Cytolocalization of actin and tubulin}

Adult virgin males were dissected in SM containing $10 \%$ (wt/ vol/ polyvinyl-pyrrolidone, and the testes were transferred to a drop of $4 \%$ paraformaldehyde in SM in a depression slide. The testes were incubated in a moist chamber for $60 \mathrm{~min}$ at room temperature and then rinsed in PBS $(\mathrm{pH} 7.0)$ three times for a total of $15 \mathrm{~min}$. Unreacted aldehydes were blocked by incubat- ing the testes in PBS and $10 \mathrm{mg} / \mathrm{ml}$ of glycine for $30 \mathrm{~min}$. For actin staining, the testes were transferred to a drop of rhodamine-conjugated phalloidin (Molecular Probes Inc., Eugene, $O R$ ) prepared according to the manufacturer's directions and incubated for $30 \mathrm{~min}$ in a moist, dark chamber. The testes were rinsed briefly in PBS (pH 7.0) and examined with a Zeiss fluorescence microscope or a Bio-Rad 600 Laser Confocal microscope. For anti-tubulin staining, the fixed testes were permeablized in $0.5 \%$ Triton X-100 in PBS for $5 \mathrm{~min}$ and then rinsed in PBS for $15 \mathrm{~min}$, followed by two rinses in PBS and $5 \%$ normal goat serum for a total of $30 \mathrm{~min}$. The testes were then incubated in a 1:200 dilution of rabbit anti- $\alpha$-tubulin serum [kindly provided by A. Adams (Kilmartin et al. 1982)] for $60 \mathrm{~min}$ and rinsed in PBS and $5 \%$ normal goat serum twice for a total of $45 \mathrm{~min}$. The testes were then stained with fluorescent secondary antibodies, rinsed, and examined as above. For visualization of nuclei, preparations were also stained with DAPI as above or with YO-PRO (Molecular Probes Inc., Eugene, OR) for confocal microscopy.

\section{Electron microscopy}

Adult virgin males were dissected in SM, and the testes were transferred to $1 \%$ formaldehyde, $1 \%$ glutaraldehyde, in SM in a depression slide. The testes were fixed in a moist chamber for 60 min at room temperature and then embedded in $1 \%$ agarose. Small agarose blocks with the tissue were incubated in the fixative overnight at $4^{\circ} \mathrm{C}$, rinsed in $10 \mathrm{mg} / \mathrm{ml}$ of lysine for $20 \mathrm{~min}$, rinsed in $\mathrm{SM}$, and then postfixed in $1 \% \mathrm{OsO}_{4}$ in $\mathrm{SM}$. Excess $\mathrm{OsO}_{4}$ was rinsed with water, and the blocks were then stained in $0.5 \%$ aqueous uranyl acetate. The blocks were then dehydrated in a graded series of ethanol and embedded in EPON/ araldite resin for sectioning. Thin sections were examined with a Philips 420 electron microscope operating at $80 \mathrm{kV}$.

\section{Molecular analysis}

DNA and RNA were isolated from worms following standard methods. A modified (Church and Gilbert 1984) method of UV cross-linking was used for Southern and Northern blot hybridizations. Differential Northern analysis was done using poly $(\mathrm{A})^{+}$RNA isolated from the following strains: Males were purified as described by Nelson et al. (1978) to $>95 \%$ from him5(e1490) (Hodgkin et al. 1979); "females," were fem-1(hc17ts) (Doniach and Hodgkin 1984) mutants raised at restrictive temperature so that they produced only oocytes and no sperm; and hermaphrodites making only sperm were fem-3(q23ts) gain-offunction mutants raised at restrictive temperature where they produce only sperm and no oocytes (Barton et al. 1987). cDNA clones were isolated from a Unizap library prepared for us from poly $(\mathrm{A})^{+}$RNA of male-enriched $(95 \%$ males) adult worms (Stratagene, La Jolla, CA). Genomic and cDNA inserts cloned into a Bluescript (Stratagene, La Jolla, CA) vector were used for dideoxy sequencing. Exonuclease III-mung bean nuclease digestion was used for generating a deletion series for sequencing (Ausubel 1994). Specific mutations in different alleles of spe-26 were identified by cycle sequencing (Murray 1989) of amplified gene products generated by polymerase chain reaction (PCR) of DNA isolated from homozygous mutants or from single mutant worms according to published methods (Williams et al. 1992). The PCR-amplified products were chloroform-phenol extracted, and $\sim 50$ fmoles of each template was used for cycle sequencing following the protocol provided in the GIBCO-BRL (Bethesda, MD) dsDNA Cycle Sequencing System. 


\section{DNA transformation}

Young adult hermaphrodites of temperature-sensitive mutants raised at the permissive temperature were used for DNA transformation rescue analysis. The genomic DNA clones were microinjected into the oocyte nucleus or the syncytium of the gonad according to published methods (Fire 1986; Mello et al. 1991). After recovery, the injected worms were allowed to lay eggs at the permissive temperature, and the $F_{1}$ embryos were transferred daily to the restrictive temperature and scored for fertility. For analysis of transformation efficiency, $p R F 4$, encoding the dominant rol-6/su1006) mutation was coinjected with the appropriate spe-26 plasmids, and the $F_{1}$ fertile progeny with the roller phenotype were selected at the appropriate temperature for further phenotypic analyses. Stable transformed lines were established from all transformations that gave fertile progeny.

\section{In situ localization of $m R N A$}

In situ localization of spe-26 transcripts was performed following the protocol described by Evans et al.(1994). Briefly, young adult hermaphrodites or young adult males were dissected in $2.5 \mu \mathrm{l}$ of PBS on a polylysine-coated slide and processed according to the protocol. Anti-sense digoxigenin-RNA probes were generated from spe-26 cDNA and hybridized to the tissue at $55^{\circ} \mathrm{C}$ for $36 \mathrm{hr}$. Excess probe was washed away, the tissue incubated in anti-digoxigenin antibody, excess antibody removed, and the color developed.

\section{Acknowledgments}

We thank Patty Jansma for the confocal micrographs, the Division of Neurosciences for use of the confocal microscope, Steve L'Hernault and Diane Shakes for kindly providing spe-26 mutant strains, and Wayne Van Voorhies for some data. Other worm strains were obtained from the Caenorhabditis elegans Genetic Stock Center supported by the National Institutes of Health (NIH). Michael Way kindly provided the scruin sequence before publication. We thank our colleagues in the laboratory for help and advice and for comments on the manuscript and thank Marilyn Kramer for preparing the manuscript. This research was supported by NIH grants GM25243 and AG11659, a University of Arizona Undergraduate Biology Research Program award to B.D., and American Cancer Society Institutional Research Support grant IN110 to J.V.

The publication costs of this article were defrayed in part by payment of page charges. This article must therefore be hereby marked "advertisement" in accordance with 18 USC section 1734 solely to indicate this fact.

\section{Note}

The spe-26 sequence has been deposited to the GenBank data library under accession no. U20142.

\section{References}

Altschul, S.F., W. Gish, W. Miller, E.W. Myers, E. W., and D.J. Lipman. 1990. Basic local alignment search tool. I. Mol. Biol. 215: 403-410.

Ausubel, F.M., ed. 1994. Current protocols in molecular biology. John Wiley \& Sons, New York.

Barton, M.K., T.B. Schedl, and J. Kimble. 1987. Gain-of-function mutations of fem-3, a sex-determination gene in Caenorhab- ditis elegans. Genetics 115: 107-119.

Bork, P. and R.F. Doolittle. 1994. Drosophila kelch motif is derived from a common enzyme fold. J. Mol. Biol. 236: 12771282.

Brandon, C. and J. Tooze. 1991. Introduction to protein structure. Garland Inc., New York.

Brenner, S. 1974. The genetics of Caenorhabditis elegans. Genetics 77: 71-94.

Burke, D.J. and S. Ward. 1983. Identification of a large multigene family encoding the major sperm protein of Caenorhabditis elegans. J. Mol. Biol. 171: 1-29.

Chang-Yeh, A., D.E. Mold, and R.C. Huang. 1991. Identification of a novel murine IAP-promoted placenta-expressed gene. Nucleic Acids Res. 19: 3667-3672.

Church, G.M. and W. Gilbert. 1984. Genomic sequencing. Proc. Natl. Acad. Sci. 81: 1991-1995.

Clark, D.V. and D.L. Baillie. 1992. Genetic analysis and complementation by germ-line transformation of lethal mutations in the unc-22 IV region of Caenorhabditis elegans. Mol.e Gen. Genet. 232: 97-105.

Devereux, J., P. Haeberli, and O. Smithies. 1984. A comprehensive set of sequence analysis programs for the VAX. Nucleic Acids Res. 12: 387-395.

Doniach, T. and J. Hodgkin. 1984. A sex-determining gene, fem1 , required for both male and hermaphrodite development in Caenorhabditis elegans. Dev. Biol. 106: 223-235.

Evans, T.C., S. L. Crittenden, V Kodoyianni, and J. Kimble. 1994. Translational control of maternal $g l p-1$ mRNA establishes an asymmetry in the C. elegans embryo. Cell 77: 183194.

Fire, A. 1986. Integrative transformation of Caenorhabditis elegans. EMBO /. 5: 2673-2680.

Hodgkin, J. 1986. Sex determination in the nematode C. elegans Analysis of tra-3 suppressors and characterization of fem genes. Genetics 114: 15-52.

Hodgkin, J., H.R. Horvitz, and S. Brenner. 1979. Non-disjunction mutants of the nematode Caenorhabditis elegans. Genetics 91: 67-94.

Kilmartin, J.V., B. Wright, and C. Milstein. 1982 . Rat monoclonal antitubulin antibodies derived by using a new nonsecreting rat cell line. J. Cell Biol. 93: 576-582.

Klass, M.R., S. Kinsley, and L.C. Lopez. 1984. Isolation and characterization of a sperm-specific gene family in the nematode Caenorhabditis elegans. Mol. Cell. Biol. 4: 529-537.

Knowles, B.A. and L. Cooley. 1994. The specialized cytoskeleton of the Drosophila egg chamber. Trends Genet. 10: 235241.

Kondo, K., J. Hodgkin, and R.H. Waterston. 1988. Differential expression of five tRNA(UAGTrp) amber suppressors in Caenorhabditis elegans. Mol. Cell. Biol. 8: 3627-3635.

Kotwal, G.J. and B. Moss. 1988. Analysis of a large cluster of nonessential genes deleted from a vaccinia virus terminal transposition mutant. Virology 167: 524-537.

L'Hernault, S.W., and P.M. Arduengo. 1992. Mutation of a putative sperm membrane protein in Caenorhabditis elegans prevents sperm differentiation but not its associated meiotic divisions. J. Cell Biol. 119: 55-68.

L'Hernault, S.W., D.C. Shakes, and S. Ward. 1988. Developmental genetics of chromosome I spermatogenesis-defective mutants in the nematode Caenorhabditis elegans. Genetics 120: 435-452.

L'Hernault, S.W., G.M. Benian, and R.B. Emmons. 1993. Genetic and molecular characterization of the Caenorhabditis elegans spermatogenesis-defective gene spe-17. Genetics 134: 769-780.

Mello, C.C., J.M. Kramer, D. Stinchcomb, and V. Ambros. 1991. 
Efficient gene transfer in $C$. elegans: Extrachromosomal maintenance and integration of transforming sequences. EMBO I. 10: 3959-3970.

Murray, V. 1989. Improved double-stranded DNA sequencing using the linear polymerase chain reaction. Nucleic Acids Res. 17: 88-89.

Nelson, G.A., K.K. Lew, and S. Ward. 1978. Intersex, a temperature-sensitive mutant of the nematode Caenorhabditis elegans. Dev. Biol. 66: 386-409.

Nelson, G.A., T.M. Roberts, and S. Ward. 1982. Caenorhabditis elegans spermatozoan locomotion: amoeboid movement with almost no actin. J. Cell Biol. 92: 121-131.

Owen, C. and D. DeRosier. 1993. A $13-\AA$ map of the actinscruin filament from the Limulus acrosomal process [published erratum appears in $/$. Cell. Biol. 123: 1621]. $/$. Cell Biol. 123: 337-344.

Perkins, L.A., E.M. Hedgecock, J.N. Thomson, and J.G. Culotti. 1986. Mutant sensory cilia in the nematode Caenorhabditis elegans. Dev. Biol. 117: 456-487.

Roberts, T.M. and S. Ward. 1982. Centripetal flow of pseudopodial surface components could propel the amoeboid movement of Caenorhabditis elegans spermatozoa. I. Cell Biol. 92: $132-138$.

Roberts, T.M., F.M. Pavalko, and S. Ward. 1986. Membrane and cytoplasmic proteins are transported in the same organelle complex during nematode spermatogenesis. I. Cell Biol. 102: $1787-1796$.

Schmid, M.F., J. Jakana, P. Matsudaira, and W. Chiu. 1993. Imaging frozen, hydrated acrosomal bundle from Limulus sperm at $7 \AA$ resolution with a $400 \mathrm{kV}$ electron cryomicroscope. I. Mol Biol. 230: 384-386.

Schmid, M.F., J.M. Agris, J. Jakana, P. Matsudaira, and W. Chiu. 1994. Three-dimensional structure of a single filament in the Limulus acrosomal bundle: Scruin binds to homologous helix-loop-beta motifs in actin. /. Cell Biol. 124: 341-350.

Senkevich, T.G., G.L. Muravnik, S.G. Pozdnyakov, V.E. Chizhikov, O.I. Ryazankina, S.N. Shchelkunov, E.V. Koonin, and V.I. Chernos. 1993 . Nucleotide sequence of XhoI O fragment of ectromelia virus DNA reveals significant differences from vaccinia virus. Virus Res. 30: 73-88.

Shakes, D.C. and S. Ward. 1989. Mutations that disrupt the morphogenesis and localization of a sperm-specific organelle in Caenorhabditis elegans. Dev. Biol. 134: 307-316.

Singer, R.H. 1992. The cytoskeleton and mRNA localization. Curr. Biol. 4: 15-19.

Sulston, J., Z. Du, K. Thomas, R. Wilson, L. Hillier, R. Staden, N. Halloran, P. Green, J. Thierry-Mieg, L. Qiu, S. Dear, A. Coulson, M. Craxton, R. Durbin, M. Berks, M. Metzstein, T. Hawkins, R. Ainscough, and R. Waterston. 1992. The C. elegans genome sequencing project: A beginning (see Comments). Nature 356: 37--41.

Van Voorhies, W.A. 1992. Production of sperm reduces nematode lifespan (see Comments). Nature 360: 456-458.

Varkey, J.P., P.L. Jansma, A.N. Minniti, and S. Ward 1993. The Caenorhabditis elegans spe- 6 gene is required for major sperm protein assembly and shows second site non-complementation with an unlinked deficiency. Genetics 133: 7986.

Ward, S. 1986. The asymmetric localization of gene products during the development of Caenorhabditis elegans spermatozoa. In Gametogenesis and the early embryo (ed. J.G. Gall), pp. 55-75. Alan R. Liss, New York.

Ward, S. and M. Klass. 1982 . The location of the major protein in Caenorhabditis elegans sperm and spermatocytes. Dev. Biol. 92: 203-208.

Ward, S., Y. Argon, and G.A. Nelson. 1981. Sperm morphogen- esis in wild-type and fertilization-defective mutants of Caenorhabditis elegans. J. Cell Biol. 91: 26-44.

Ward, S., E. Hogan, and G.A. Nelson. 1983. The initiation of spermiogenesis in the nematode Caenorhabditis elegans. Dev. Biol. 98: 70-79.

Waterston, R.H. 1981. A second informational suppressor SUP-7 X, in Caenorhabditis elegans. Genetics 97: 307-325.

Way, M., M. Sanders, C. Garcia, J. Sakai, and P. Matsudaira. 1994. Sequence and domain organization of scruin, an actincrosslinking protein in the acrosomal process of Limulus sperm. J. Cell Biol. 128: 51-60.

Williams, B.D., B. Schrank, C. Huynh, R. Shownkeen, and R.H. Waterston. 1992. A genetic mapping system in Caenorhabditis elegans based on polymorphic sequence-tagged sites. Genetics 131: 609-624.

Wills, N., R.F. Gesteland, J. Karn, L. Barnett, S. Bolten, and R.H. Waterston. 1983. The genes sup- $7 X$ and sup-5 III of C. elegans suppress amber nonsense mutations via altered transfer RNA. Cell 33: 575-583.

Wilson, R., R. Ainscough, K. Anderson, C. Baynes, M. Berks, J. Bonfield, J. Burton, M. Connell, T. Copsey, J. Cooper, et al. 1994. 2.2 Mb of contiguous nucleotide sequence from chromosome III of C. elegans. Nature 368: 32-38.

Wolf, N., D. Hirsh, and J.R. McIntosh. 1978. Spermatogenesis in males of the free living nematode. J. Ultrastruct. Res. 63: 155-169.

Xue, F. and L. Cooley. 1993. kelch encodes a component of intercellular bridges in Drosophila egg chambers. Cell 72: 681-693. 


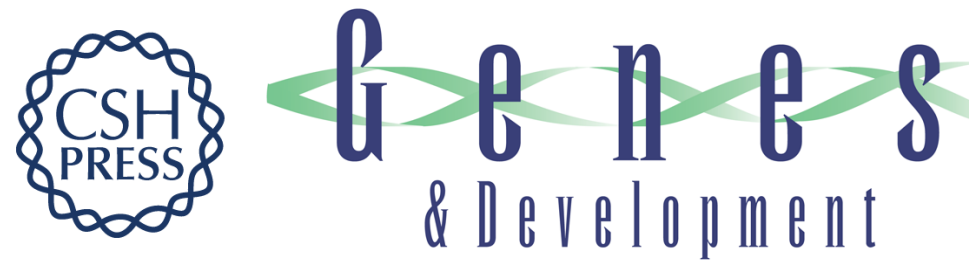

\section{The Caenorhabditis elegans spe-26 gene is necessary to form spermatids and encodes a protein similar to the actin-associated proteins kelch and scruin.}

J P Varkey, P J Muhlrad, A N Minniti, et al.

Genes Dev. 1995, 9:

Access the most recent version at doi:10.1101/gad.9.9.1074

References This article cites 48 articles, 20 of which can be accessed free at: http://genesdev.cshlp.org/content/9/9/1074.full.html\#ref-list-1

License

Email Alerting Receive free email alerts when new articles cite this article - sign up in the box at the top Service right corner of the article or click here.

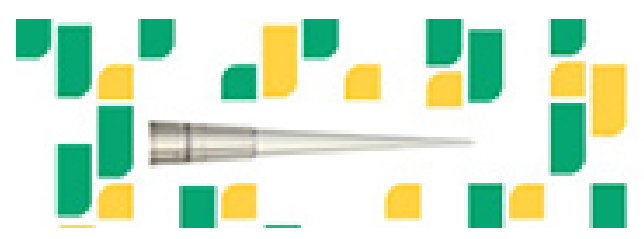

Focused on your science. 